\title{
A systematic review of interventions to improve acute hospital care for people with dementia
}

Melanie Karrer ( $\square$ melanie.karrer@fhsg.ch)

Center for Dementia Care, Institute of Applied Nursing Sciences, FHS St.Gallen, University of Applied Sciences, Departement of Health

https://orcid.org/0000-0003-0031-2840

Angela Schnelli

Center for Dementia Care, Institute of Applied Nursing Sciences, FHS St.Gallen, University of Applied Sciences, Departement of Health

Adelheid Zeller

Center for Dementia Care, Institute for Applied Nursing Sciences, FHS St.Gallen, University of Applied Sciences, Departement of Health

Hanna Mayer

Departement fo Nursing Science, University of Vienna

\section{Research article}

Keywords: Dementia, Cognitive impairment, Acute hospital, Acute care, Systematic review

Posted Date: January 30th, 2020

DOI: https://doi.org/10.21203/rs.2.22248/v1

License: @ (i) This work is licensed under a Creative Commons Attribution 4.0 International License. Read Full License

Version of Record: A version of this preprint was published at Geriatric Nursing on May 1st, 2021. See the published version at https://doi.org/10.1016/j.gerinurse.2021.03.006. 


\section{Abstract}

Background

People with dementia are confronted with negative consequences due to hospital stays. When developing new interventions to improve the care of people with dementia in acute care hospitals, it is crucial to have a comprehensive overview of the previous interventions tested in this field and to know the investigated outcomes and effects.

Methods

We conducted a systematic review of interventional studies to provide an overview of interventions targeting the care situation of patients with dementia in acute care hospitals. We included trials with interventional study designs and systematic reviews of interventional studies with no restrictions regarding the outcomes. We searched five electronic databases, conducted a hand search of journals and performed forward and backward citation tracking of the included studies. For risk of bias assessment, we used the Cochrane Collaboration's tool for assessing risk of bias in randomised trials, ROBANS (for non-randomised controlled trials) and AMSTAR (for systematic reviews). We provide tabular and narrative summaries of the findings.

Results

Nineteen studies met the inclusion criteria. he findings indicated a broad range of interventions and outcomes. We categorised the interventions into nine intervention types: educational programmes, family-/person-centred programmes, use of specially trained nurses, volunteer programmes, delirium management programmes, special care units and inpatient rehabilitation interventions. Staff outcomes were primarily investigated, followed by patient outcomes. Outcomes for relatives were only reported in three of the included studies. Educational programmes were the most commonly reported intervention type and showed improvements in staff outcomes. Family-/person-centred care programmes, use of specially trained nurses and delirium management programmes were able to improve patient-related outcomes, e.g. delirium severity, functional performance and rehospitalisation rates. Rehabilitation interventions after hip fractures and special care units for people with dementia showed hardly significant effects.

\section{Conclusions}

Although the included interventional studies were able to show improved outcomes for staff, relatives and patients, the evidence is insufficient to declare which interventions are effective in improving care for people with dementia in acute care hospitals. Future research should focus on patient and family caregiver outcomes. Furthermore, interventions addressing relatives, interprofessional collaboration and the entire practice culture are needed.

\section{Background}

Although the prevalence rates for dementia in the acute hospital setting vary in the literature, it is estimated that about $20-25 \%$ of hospital patients have dementia [1, 2]. Thereby, about $56 \%$ of dementia cases are not diagnosed or recognised by healthcare staff [3]. The International Classification of Diseases (ICD-11) defines dementia as an 'acquired brain syndrome characterized by a decline from a previous level of cognitive functioning with impairment in two or more cognitive domains (such as memory, executive functions, attention, language, social cognition and judgment, psychomotor speed, visuoperceptual or visuospatial abilities)'. Cognitive impairment influences a person's independence [4]. The psychological and social needs of persons with dementia are love, comfort, attachment, occupation, inclusion and identity [5]. Acute care hospitals are defined as 'inpatient medical facilities providing therapy for severe illness or injury with an average length of stay of 30 days or fewer' [6]. They are also described as institutions with rigid cultures and inflexible routines and schedules. As a consequence, older persons are disadvantaged by this system [7]. The individual needs of people with dementia are not met in acute care hospitals; thus, they do not receive adequate care $[8,9]$. Structural aspects, such as a lack of staff knowledge and time constraints due to inadequate staffing levels, as well as a non-supportive practice culture and the physical environment of the hospital, are reasons for this problem [8]. Furthermore, people with dementia are away from familiar persons, may have pain, do not know where they are and do not know what is happening [10]. Thus, people with dementia can react with emotional distress and exhibit behaviours, such as agitation, crying, restlessness, aggression, anger or calling and shouting out [10]. It was shown that hospital stays have negative effects on the symptoms of dementia, such as decreases in cognitive function and independence [2]. An analysis of about 19000 hospital admissions showed that people with dementia have significantly longer hospital stays than patients without cognitive impairment in the same age group and are more likely to be discharged to a nursing home for the first time [11]. Furthermore, people with dementia have a high risk of developing delirium during their acute hospital stay. Margiotta, Bianchetti, Ranieri and Trabucci[12] showed that $59 \%$ of patients with dementia and $13 \%$ of patients without dementia developed delirium. Furthermore, delirium causes prolonged hospital stays, a lower cognitive and functional status and a higher mortality rate $[11,12]$.

This problematic situation has led to many initiatives to improve the care of patients with dementia in the acute hospital setting. Recent literature reviews have summarized crucial aspects of good quality of care for persons with cognitive impairment in acute care hospitals[8, 13]. Staff knowledge and confidence, a supportive practice culture, an adequate physical environment and clinical experts and supportive leaders were identified as factors for good quality of care for persons with dementia. Furthermore, family- and person-centredness, adequate assessments and interventions and continuous and collaborative care were also identified $[8,13]$. Naef et al. $[8]$ pointed out that there are promising strategies to promote good quality of care that need to be systematically reviewed.

There are systematic reviews focusing on specific interventions for persons with dementia in the acute hospital setting, e.g. on educational and training interventions [14] or on special care units for patients with dementia [15]. When developing new interventions for people with dementia in acute care hospitals, it is crucial to have a comprehensive overview of the previous interventions tested in this field and to know the investigated outcomes. To our knowledge, no existing systematic review includes all types of interventions and outcomes. This review is part of a larger project that aims to develop a care model for 
persons with dementia in the acute hospital setting in Switzerland. Recent knowledge about the investigated interventions will inform the development of this care model and will be important when developing and evaluating other initiatives, programmes or interventions in this field.

\section{Objective}

The aim of this review was to provide a systematic overview of interventions targeted to improve the care of patients with dementia and cognitive impairment on normal wards in acute care hospitals. This review will show which kinds of interventions were tested in this field, which outcomes were reported, and which effects were shown. This knowledge can contribute to the development of improved and evidence-based care for people with dementia in acute care hospitals.

A systematic review of interventional studies was conducted to gather the best possible research evidence to develop the evidence base in the area of dementia care in hospitals and to inform a future care model for people with dementia in the acute hospital setting.

\section{Methods}

\section{Criteria for considering studies for this review}

We included trials with (1) an interventional study design and reviews of interventional studies, (2) published in journals, books or as grey literature in (3) English or German (4) since 2009. The studies had to be (5) conducted in the acute hospital setting, and they had to (6) examine any intervention targeting the care situation of (7) patients with dementia (including all types and stages and all ages) in this setting. We also included studies that focused on patients with cognitive impairment in general (8) because, in the hospital setting, the dementia diagnosis is often not clear [1]. Outcomes of interest were any patient outcomes and any formal or informal caregiver outcomes. Since patient outcomes may be influenced by various factors, such as the knowledge of the caregiver and the interaction between the person and the formal or informal caregiver, outcomes on the patient, as well on the formal or informal caregivers, were of interest.

We excluded trials with (1) no interventional study design, as well as (2) abstracts and (3) conference proceedings. We did not include studies that focused on interventions outside the acute hospital setting (such as interventions made to avoid hospital admissions or interventions after hospital discharge), those focused on pharmacological interventions or those focused solely on persons with delirium (without dementia) (4). We also excluded studies that investigated interventions conducted in the psychiatric setting, special dementia units (except if the special dementia unit was the intervention), intensive care units or emergency departments.

Two reviewers independently screened the titles and abstracts. Afterwards, we obtained the full texts of the remaining references, and the two reviewers read them independently. We solved all conflicts by discussion. The flow chart (Fig. 1) shows the selection process, depicting the number of identified, excluded and included references in detail.

\section{Search strategy}

A comprehensive literature search was conducted in January to March 2019. The following electronic databases were searched (from 01/2009 until 01/2019): CINAHL, MEDLINE via PubMed, Web of Science, PsycINFO via Ovid and the Cochrane Library. Further studies were searched by forward and backward citation tracking of included studies using the Scopus database. Additionally, a free web search was conducted in Google Scholar, as well as a hand search of relevant journals not indexed in the databases (Journal/ISSN: Pflegezeitschrift/2520 - 1816, HeilberufeScience/2190 - 2100, Angewandte Gerontologie Appliquée/2297-5179 and Klinische Pflegeforschung/2365-7863).

We used the following search terms in combination with the operators AND and OR: dementia, Alzheimer, hospital, acute care, acute hospital care, inpatients, hospital units, experimental Studies, quasi-experimental studies, randomized controlled trial, controlled clinical trial, randomised, random allocation, trial, experiment, quasi-experiment, clinical trial, intervention, before-after, pretest-posttest, nonrandomized, evaluation and repeated measures design. We used $\mathrm{MesH}$ terms where available and used the $\mathrm{MesH}$ term as a search term as well. With this sensitive approach, we aimed to find all relevant interventional studies in the field of dementia in hospitals. The search strings for all databases are available in Additional file 1.

One author developed the search strategy, and another author checked it with the PRESS-Guideline [16] before it was conducted. We registered the review protocol in PROSPERO (https://www.crd.york.ac.uk/PROSPERO/): CRD42018111032.

\section{Data extraction and analysis}

We extracted data with a predefined data extraction sheet. From each study, one author extracted general information (year, country and publication type), aim, study design, setting, intervention and comparisons, characteristics of the participants (as well as inclusion and exclusion criteria), outcomes and measures and the findings. Data extraction was controlled by a research assistant. We performed a narrative synthesis of the included studies.

\section{Risk of bias assessment}

To assess the risk of bias of randomised controlled trials, we used the Cochrane Collaboration's tool for assessing risk of bias in randomised trials [17]. For non-randomised controlled trials and before-after studies, we used ROBANS [18]. Risk of bias of systematic reviews was assessed with AMSTAR 2 [19]. Two authors independently assessed the risk of bias of the included studies. We solved discrepancies by discussion.

\section{Results}


The initial search yielded 5957 records after duplicates were removed. We retrieved 60 for the full-text review. In total, 19 articles met the inclusion criteria (see the flow chart in Figure 1). Most of the interventional studies had a before-after design [20-28] $(n=9)$. One was a cluster-randomised controlled trial [29], one used a repeated measures design [30] and three were controlled clinical trials [31-33]. Five of the studies were systematic reviews [14, 15, 34-36]. The systematic reviews were published in 2015 [35] $(n=1), 2017[34,36](n=2)$ and $2019[14,15](n=2)$. The interventional studies were published between 2011 and 2019, and only three studies were published before 2015 [20, 27, 29].

Of the interventional studies, five studies were conducted in Australia [22, 23, 28, 32, 33], four in the United States [20, 24, 29, 30], two in the United Kingdom [21, 26] and one each in Canada [31], Germany [27] and Switzerland [25]. All five systematic reviews were carried out in the UK [14, 15, 34-36]. The included interventional studies presented a range of interventions for people with dementia in the acute hospital setting, including educational interventions for healthcare staff $[21,24,26,28,31](n=5)$ or for volunteers working with people with dementia in hospital [27] $(n=1)$. Three studies focused on family-/person-centred programmes [22, 23, 30], and two studies were on specially trained nurses [29, 32]. Further studies investigated a volunteer programme [33] $(n=1)$, a delirium management programme for people with cognitive impairment [25] $(n=1)$ and a special non-pharmacological intervention [20] $(n=1)$. The systematic reviews were on educational interventions $[14,34](n=2)$, special care units for people with dementia [15] ( $n=1)$, inpatient rehabilitation intervention for people with dementia after hip fracture on surgical units [35] $(n=1)$ and music therapy [36] $(n=1)$. Table 1 provides information about the characteristics of the included studies.

\section{Risk of bias of included studies}

The main weakness of the non-randomized interventional studies was in the selection of participants because most studies did not use a control group or used a historic control group. The blinding of outcome assessments was not fulfilled in nine of the studies, and the risk for selective outcome reporting was rated as high or unclear in all the non-randomized studies. Furthermore, we rated the overall risk of bias for the randomized controlled trial as high. One systematic review showed very good quality in nearly all domains [35], and the others showed good overall quality with concerns regarding some domains. A detailed description and risk of bias table is provided in Additional file 2.

\section{Educational programmes}

\section{Intervention characteristics}

Three of the educational interventions for healthcare staff were aimed at different hospital professions (nurses, doctors, allied health professionals, occupational/physiotherapists) $[21,26,31]$. Two focused on communication skills and used experiential and interactive strategies [21, 26]. One focused on person-centred care, communication, self-protection and team/patient/family debriefing [31]. One was targeted to prepare nurses and change leader nurses for the implementation of a systematic nurse-caregiver conversation [28]. One educational intervention was an online training programme for nursing assistants and allied healthcare workers and contained information on dementia-friendly principles, communication and wandering and falls [24]. The volunteer educational programme studied by Eggenberger et al. [27] included contents, such as the life situations of older people, communication, dying in hospital, activities with people with dementia and the role and identity of volunteers. The two systematic reviews about educational interventions included interventions targeted at healthcare staff from different professions, with nurses representing the largest group [14, 34]. Details about intervention characteristics can be found in Table 1.

\section{Reported outcomes and effects}

The following outcomes were assessed in the studies about educational interventions: knowledge, self-efficacy and confidence of staff, beliefs and attitudes of staff, burnout, satisfaction with the care of people with dementia, the number of palliative care consultations and the change in aggressive behaviour incidents.

Four interventional studies identified a significant effect regarding knowledge of healthcare staff [24, 26, 28] or volunteers [27]. There was a significant increase in knowledge after the end of a two-day communication training course for nurses, doctors and allied health professionals [26] and after an online training tool for nursing assistants and allied health workers [24]. The systematic reviews of Abley et al. [14] and Scerri et al. [34] showed mixed results, though most included studies showed significant improvement in knowledge. Furthermore, self-rated evaluations of sense of competence, confidence and selfefficacy significantly improved in three interventional studies describing training programmes for healthcare professionals [21, 26, 31]. In the systematic review of Scerri et al. [34], confidence of staff was significantly improved in five included studies, and self-efficacy significantly improved in two studies. In both studies that measured dementia confidence in the review of Abley et al. [14], a significant increase in confidence immediately post-intervention was measured; however, at 120 days post-intervention, confidence levels declined significantly in one study.

Self- assessed communication skills were not improved in the volunteer training study [27], and another study showed that only three of 11 communication behaviours showed significant change [26]. Scerri et al. [34] described improved documentation and risk assessment, as well as a reduction in the use of sedations. One study included in the review of Scerri et al. [34] described less aggressive incidents pre-training compared to post-training. Table 2 provides an overview of all reported outcomes and effects. Detailed information about the findings of the included studies and statistical data can be found in Additional file 3. 


\section{Special non-pharmacological interventions}

\section{Intervention characteristics}

One study focused on 'simple pleasures' interventions for hospital patients with late stage dementia, where items, such as balls filled with rice or fleececovered warm water bottles, were handed out to patients and specifically targeted to reduce identified expressions of unmet needs [20]. The systematic review about music therapy planned to include interventions for patients with cognitive impairment in hospital conducted by a music therapist, but no studies fulfilled the inclusion criteria [36].

\section{Reported outcomes and effects}

The study about the simple pleasures intervention only reported on the outcome of agitation/aggression [20]. Wierman et al. [20] were not able to show a significant effect of the simple pleasures intervention, but reported that there was a trend towards an improvement in agitation. Table 2 provides an overview of all reported outcomes and effects.

\section{Delirium management programme}

\section{Intervention characteristics}

Hasemann et al. [25] investigated a nurse-led interdisciplinary programme for the detection and treatment of delirium in patients with cognitive impairment. The programme contained an educational package, systematic screening of patients over 70 for cognitive impairment and the implementation of interdisciplinary interventions when delirium occurred.

\section{Reported outcomes and effects}

The study reported on outcomes regarding delirium severity/duration and on benzodiazepine use [25]. Delirium severity decreased significantly on the adherent wards. This effect was evident from the first to the second day of delirium and over the complete course of the delirium. Table 2 provides an overview of all reported outcomes and effects.

\section{Inpatient rehabilitation intervention}

\section{Intervention characteristics}

The systematic review of rehabilitation strategies after hip fracture surgery included patients with any form of dementia. It investigated enhanced interdisciplinary inpatient (and home-based) rehabilitation and care models and geriatrician-led inpatient management [35].

\section{Reported outcomes and effects}

Smith et al [35] reported on patient outcomes, such as functional performance and mortality, discharge destination and length of hospital stay. One study included in the systematic review of Smith et al. [35] about enhanced interdisciplinary rehabilitation showed a non-significant trend towards better function performance through the intervention. One study showed a greater proportion of participants in the intervention group regaining pre-fracture walking levels and better ADL performance at 3 and 12 months but not at 24 months [35]. Mortality was not different between the groups in two studies at 3 or 12 months [35].

In two studies comparing enhanced interdisciplinary inpatient and home-based rehabilitation with conventional rehabilitation, a difference between the groups in favour of the intervention was measured regarding discharge destination at 3 months but not at 12 months. There was a significant difference for people with mild or moderate dementia at 3 months but not at 12 months. No difference was shown for those with severe dementia [35]. Table 2 provides an overview of all reported outcomes and effects.

\section{Family-/person-centred programmes}

\section{Intervention characteristics}

Two of the family-centred programmes were based on the 'TOP5 strategy', were staff defines up to five personalised care strategies with the family caregivers to enhance person-centred care [22, 23]. Another study tested the impact of a combination of function-focused care and an educational empowerment intervention for family caregivers, where care pathways were developed together by staff and families [30]. 


\section{Reported outcomes and effects}

The three studies reporting on family- or person-centred programmes reported on a broad range of outcomes, e.g. use of one-to-one nursing care, antipsychotic medication use, staff confidence, ADL performance, walking performance, delirium severity of patients, average length of stay, anxiety, depression or role strain of family caregivers.

One-to-one nursing care, which is used 'in cases where regular staffing levels are not equipped to provide care, leaving the patient, other patients or staff at risk of negative outcomes' [23], decreased significantly in two studies [22, 23].

One study showed a significant improvement in staff's confidence in caring for patients with dementia after introduction of the intervention compared to preimplementation. This effect lasted between 6 and 12 months [22]. Another study showed no difference in the level of confidence at three time points and no improvement in staff's comfort in engaging with family carers [23]. With their family-and function-focused care programme, Boltz et al. [30] showed a significant improvement in ADL performance and a significant decrease in the delirium severity of patients who received the intervention compared to function-focused care education alone. Furthermore, the intervention showed a positive effect regarding readmission within 30 days [30]. Outcomes for family caregivers were significantly improved regarding preparedness for caregiving, anxiety [30] and satisfaction regarding communication with the staff [22]. Table 3 provides an overview of all reported outcomes and effects.

\section{Use of specially trained nurses}

\section{Intervention characteristics}

One study investigated the upskill of registered nurses to so-called 'cognition champions' who should develop action plans for practice change [32]. Another study compared a transition programme conducted from advanced practice nurses with the care of 'resource nurses' (upskilled registered nurses) and with an augmented standard care programme (research assistants who communicated cognitive screening results to staff) [29].

\section{Reported outcomes and effects}

As the programme studied by Naylor et al. [29] included an intervention for the transition from hospital to home, led by an advanced practice nurse, the study focused on outcomes regarding the rehospitalisation of patients with cognitive impairment. Besides patient outcomes, such as agitation or confusion, Travers et al. [32] also reported on staff outcomes, e.g. behaviour of staff and assessment of cognitive impairment.

The 'cognition champions' intervention led to a significant increase in the number of patients assessed for cognitive impairment with a standardized tool at the time of hospital admission, whereas the frequency of informal assessment of patients' cognitive impairment by nurses showed no significant effect [32]. Furthermore, no significant change was observed in nurses' behaviours on the acute care hospital wards based on five pre-defined behaviours, e.g. the nurse explains an action in easily understandable terms [32]. Regarding patient outcomes, Travers et al. [32] did not observe a significant change in patient activity (number of patients doing nothing vs number of patients engaged in some activity), signs of agitation or pain through the 'cognition champions' programme.

Patients receiving a transitional care model intervention led by an advanced practice nurse had a longer time to first rehospitalisation or death than the patients in the augmented standard care or the resource nurse care programme. This difference was statistically significant at 30 and 60 days between augmented standard care and the transitional care model [29]. Table 3 provides an overview of the outcomes and the effects.

\section{Volunteer programme}

\section{Intervention characteristics}

One study investigated a person-centred volunteer programme, where volunteers were trained on dementia, delirium and their role and received support from implementation staff. Volunteers provided care like that of a family caregiver, including orientation support, interaction with others, engagement in therapeutic activities, promoting the use of visual and hearing aids, assisting with drinking and eating and encouraging regular walking [33].

\section{Reported outcomes and effects}

The study about a volunteer programme for people with cognitive impairment in hospitals reported on an organisational outcome-the proportion of patients who required one-to-one supervision. Furthermore, patient outcomes, such as length of stay, readmission rate, falls and medication use, were described [33]. It was shown that a significantly smaller proportion of patients in the intervention group required one-to-one supervision than in the historic control group [33]. Although, hospital stays were longer in the intervention group, 28-day readmission rates were significantly lower for the patients receiving volunteer sessions. There were no significant differences in the proportion of patients who were discharged to a residential care facility for the first time after the hospital stay. Table 3 provides an overview of the outcomes and the effects. 


\section{Special care units for people with dementia}

\section{Intervention characteristics}

The systematic review comparing special care units within general hospitals for patients with dementia to standard care wards included acute care hospital inpatients of any age with any form of dementia [15].

\section{Reported outcomes and effects}

Special care units for people with dementia in the acute hospital setting were investigated in one systematic review [15]. Patient outcomes, such as mortality, length of stay, delirium incidence or the use of antipsychotic medications, as well as staff outcomes, such as documentation of treatment decisions, drug history or discharge plans, were reported. Family caregiver outcomes were strain and psychological well-being. No significant differences regarding mortality were found between special care units and standard care wards [15].

Special care units showed non-significant improvements in readmission rates, and patients on the special care units were non-significantly more likely to be discharged to their original home and non-significantly less likely to get discharged to a new care home [15]. Although patients on the special care units were significantly often in a positive mood or engaged, no significant difference was found regarding the rates of behavioural and psychological symptoms of dementia [15]. Incidence of delirium was slightly, but not significantly, greater on the special care units, and new prescriptions of antipsychotic medications were slightly, but not significant, greater [15]. Furthermore, no significant differences were shown for carer strain and carer psychological well-being [15]. Table 3 provides an overview of the outcomes and the effects.

\section{Discussion}

This systematic review provides a comprehensive overview of interventional studies and systematic reviews that investigate interventions targeting the care situation of patients with dementia in acute care hospitals. The findings indicate a broad range of different interventions, outcomes and measurements of these outcomes. We categorised the interventions into eight intervention types: educational programmes, family-/person-centred programmes, specially trained nurses, volunteer programmes, delirium management programmes, special care units and inpatient rehabilitation interventions.

Educational programmes were the most commonly reported intervention type among the included studies; six interventional studies and two systematic reviews (including 22 studies relevant to this review) focused on dementia education for healthcare professionals in the acute hospital setting. The studies about educational interventions predominantly reported on outcomes for the healthcare staff, e.g. knowledge, sense of competence, confidence, beliefs and attitudes, which improved significantly in most of the studies. When it comes to more complex staff outcomes, such as a change in behaviour or a change of practice, improvements were not reached in most of the studies. This demonstrates that improved knowledge does not necessarily mean improved clinical expertise. As Benner et al. [37] pointed out, it is not possible to address interpersonal and relational responsibilities and situational discernment with technique or formal knowledge alone. Furthermore, patient outcomes were only reported in one study, while outcomes for the relatives were not reported in any of the studies. Thus, the impact of these interventions for applied practice remains unclear. The results do not demonstrate what amount of the gained knowledge and improved attitudes of the healthcare professionals reached the patients with dementia and their relatives. A critical synthesis of the evidence about dementia care education in hospitals pointed out that the sustainability of the effects was 'largely unknown' because of poor follow-up outcomes [38]. The results of our review confirm this statement. Furthermore, Abley et al. [14] demonstrated that, while knowledge and confidence of staff remained stable in three hospitals after four months, it declined significantly in one hospital. Scerri et al. [34] reported that the long-term sustainability of the educational interventions was unclear. In contrast, Sampson et al. [21] showed an improved sense of competence of healthcare staff three months after education, and another study included in our review showed an increase in the knowledge of the healthcare staff after six months [28].

It seems important to update the education of healthcare staff to promote the long-term sustainability of the intervention effect. The optimal duration of education updates is still unclear. Future studies should focus on this issue by investigating long-term follow-up of educational interventions in dementia care in the acute hospital setting.

In addition, to ensure that the knowledge and confidence of staff within a changed practice reaches the patients, it is crucial to combine educational interventions with other interventions. Our review provides an overview of such interventions. Three of the included studies reported on family-/person-centred programmes, where important care principles or care pathways were defined and discussed with the families. It is notable that one of these studies did not report on family caregiver outcomes at all [23], and one study only reported on one family caregiver outcome (satisfaction) [22]. Although family caregivers were asked in a survey about the impact of the intervention on their relative, this was not assessed pre-implementation; therefore, differences could not be observed. Boltz et al. [30], who investigated a family-centred programme with different components (including environmental adaptions, ongoing training of staff and defining an individual care pathway), included five family caregiver outcomes and was able to show significant improvements regarding preparedness for caregiving and anxiety. Patient outcomes were also considered and showed improvements in functional performance, delirium severity and readmission to hospital [30]. Outcomes representing person-centredness, such as satisfaction with care, involvement with care, feeling of well-being and creating a therapeutic culture, as defined by McCormack and McCance [39], were not sufficiently considered in the included studies.

Across all the studies, it can be observed that outcomes for family caregivers were reported rarely (only in two interventional studies and one systematic review). 
As a meta-synthesis of qualitative studies shows, relatives of people with dementia experience many negative aspects of care in hospital and are worried and highly burdened because of this [40]. Family caregivers are crucial for the provision of person-centred care for people with dementia [41] and are thus underrepresented in the included interventional studies.

The following are examples of the reported patient outcomes in the included studies: mortality, length of hospital stays, readmission to hospital, incidence of falls, functional performance and delirium severity/duration/incidence, as well as agitation and behavioural and psychological symptoms of dementia. Recent literature has shown that people with dementia in hospitals have high risks for longer hospital stays [42], delirium [12], functional decline [43] and reacting with behavioural and psychological symptoms [2]. Thus, important aspects of consequences for people with dementia in acute care hospitals are covered with these outcomes. However, a meta-synthesis of qualitative studies shows the perspective of persons with dementia on the acute care hospital stay. Hospital care and the hospital environment caused anxiety and distress, a lack of control, worries about the future, distrust and feelings of social exclusion and of uncertainty [44]. These aspects were not addressed in the reported outcomes. Thus, the patient perspective has not been sufficiently considered. Given the identified aspects for good quality of care for persons with cognitive impairment in acute care hospitals in recent literature [8], it becomes clear that the reported interventions in the included studies cover the following aspects: staff knowledge and confidence (educational programmes), family- and personcentredness (family-/person-centred programmes), clinical experts (specially trained nurses) and adequate physical environment (special care units). Furthermore, Naef et al. [8] described caring relationships (addressed in the family-/person-centred care interventions), adequate assessments (specially trained nurses, educational interventions) and interventions (educational interventions) and continuous and collaborative care (specially trained nurses, family-/person-centred programmes, volunteer programme). Although different professions were involved in the educational interventions and in the preparation trainings and education for interventions, interprofessional collaboration was not specifically addressed in the interventions. Furthermore, a supportive clinical leadership and practice culture, which Naef et al. [8] also identified as important for the provision of good quality of care for persons with dementia, was not addressed in the included interventional studies.

\section{Strengths and limitations}

A strength of this review is the broad and comprehensive search with the selection of studies performed independently by two researchers. With this sensitive approach, we were able to create a systematic overview of interventional studies in dementia care in the acute hospital setting. Since complex interventions are frequently not evaluated with conventional methodological approaches, such as randomised controlled trials [45], we opened our inclusion criteria to all studies that implemented an intervention and tested it with quantitative methods. Nevertheless, with the exclusion of qualitative findings, cohort studies and case studies, we were perhaps unable to find the most complex interventions in this field. Through our decision to not only include studies that did not solely report on people with dementia but also studies on people described as having 'cognitive impairment', representing symptoms of dementia but not the diagnosis (because this is not always given in the acute hospital setting), we made sure not to exclude any relevant studies. However, because of this, the inclusion and exclusion of studies concerning this criterion were not always highly selective.

\section{Conclusions}

This systematic review of interventions to improve hospital care for people with dementia provides a comprehensive overview of reported interventions, outcomes and effects. Interventions, such as the use of specially trained nurses, family-/person-centred programmes and delirium management programmes, were able to influence organisational, staff, family caregiver and patient-related outcomes. Educational interventions were commonly investigated and showed improvements, especially in staff outcomes, including their knowledge and confidence. However, the evidence is insufficient to declare which interventions are effective in improving care for people with dementia in acute care hospitals.

Future research should focus more on patient and family caregiver outcomes. Furthermore, interventions addressing the family or relatives of the person with dementia, interventions that focus on interprofessional collaboration and studies of the entire practice culture are needed.

\section{Abbreviations}

ADL= Activities of Daily Living

AMSTAR $=$ A Measurement Tool to Assess Systematic Reviews

CINAHL= Cumulative Index to Nursing and Allied Health Literature

MEDLINE= Medical Literature Analysis and Retrieval System Online

PRESS=Peer Review of Electronic Search Strategies

RCT = Randomised Controlled Trial

RoB $=$ Risk of Bias

ROBANS=Risk of Bias Assessment for Non-randomized Studies

\section{Declarations}

Ethics approval and consent to participate: Not applicable 
Consent for publication: Not applicable

Availability of data and materials: All data generated or analysed during this study are included in this published article and its supplementary information files.

Competing interests: The authors declare that they have no competing interests.

Funding: Funding was obtained from Stiftung Pflegewissenschaft Schweiz. The funding body had no influence on the study design, the collection and analysis process, the interpretation of the data or the writing of the manuscript.

Authors' contributions: All authors were responsible for the conception of the study design. MK and AZ designed the search strategy. MK and AS conducted the literature search, the selection of the articles and the risk of bias assessment. MK and AS were responsible for data extraction. Data analysis was conducted by MK and discussed with AS, AZ and HM. MK was responsible for writing the first draft of the paper. All authors substantively edited the manuscript. All authors read and approved the final manuscript.

Acknowledgements: We gratefully acknowledge the control of data extraction by Ines Hollenstein.

\section{References}

1. Pinkert C, Holle B. Menschen mit Demenz im Akutkrankenhaus. Literaturübersicht zu Prävalenz und Einweisungsgründen. Z Gerontol Geriatr. 2012;45:728-34. doi:10.1007/s00391-012-0319-1.

2. Alzheimer's Society. Counting the cost - Caring for people with dementia on hospital wards. 2009. http://www.alzheimers.org.uk/site/scripts/documents_info.php?documentID=1199. Accessed 14 Sep 2015.

3. Jackson TA, Gladman JRF, Harwood RH, MacLullich AMJ, Sampson EL, Sheehan B, Davis DHJ. Challenges and opportunities in understanding dementia and delirium in the acute hospital. PLoS Med. 2017;14:e1002247. doi:10.1371/journal.pmed.1002247.

4. World Health Organization. ICD-11 Version 04/2019. 2019. https://icd.who.int/browse11/I-m/en\#/http://id.who.int/icd/entity/546689346.

5. Kitwood T. Demenz. Der person-zentrierte Ansatz im Umgang mit verwirrten Menschen. Bern: Verlag Hans Huber; 2013.

6. Medical Dictionary for the Health Professions and Nursing. acute care hospital. 2012. https://medicaldictionary.thefreedictionary.com/acute+care+hospital. Accessed 13 Sep 2019.

7. Parke B, Hunter KF. The care of older adults in hospital: if it's common sense why isn't it common practice? J Clin Nurs. 2014;23:1573-82. doi:10.1111/jocn.12529.

8. Naef R, Ernst J, Bürgi C, Petry H. Quality of acute care for persons with cognitive impairment and their families: A scoping review. Int J Nurs Stud. 2018;85:80-9. doi:10.1016/j.jinurstu.2018.05.006.

9. Dewing J, Dijk S. What is the current state of care for older people with dementia in general hospitals? A literature review. Dementia (London) 2016. doi:10.1177/1471301213520172.

10. Petty S, Dening T, Griffiths A, Coleston DM. Meeting the Emotional Needs of Hospital Patients With Dementia: A Freelisting Study With Ward Staff. Gerontologist 2018. doi:10.1093/geront/gny151.

11. Fogg C, Meredith P, Bridges J, Gould GP, Griffiths P. The relationship between cognitive impairment, mortality and discharge characteristics in a large cohort of older adults with unscheduled admissions to an acute hospital: a retrospective observational study. Age Ageing. 2017;46:794-801. doi:10.1093/ageing/afx022.

12. Margiotta A, Bianchetti A, Ranieri P, Trabucci M. Clinical characteristics and risk factors of delirium in demented and not demented elderly medical inpatients. The Journal of Nutrition, Health and Aging. 2006;10:535-9.

13. Handley M, Bunn F, Goodman C. Dementia-friendly interventions to improve the care of people living with dementia admitted to hospitals: a realist review. BMJ Open. 2017;7:e015257. doi:10.1136/bmjopen-2016-015257.

14. Abley C, Dickinson C, Andrews Z, Prato L, Lindley L, Robinson L. Training interventions to improve general hospital care for older people with cognitive impairment: systematic review. The British journal of psychiatry. 2019;214:201-12. doi:10.1192/bjp.2019.29.

15. McCausland BMS, Patel HP, Amin J, Baldwin DS, Loughran K, Osman-Hicks VC. A systematic review of specialist inpatient dementia care services versus standard inpatient dementia care in acute hospitals. Aging Clin Exp Res. 2019.

16. McGowan J, Sampson M, Salzwedel DM, Cogo E, Foerster V, Lefebvre C. PRESS Peer Review of Electronic Search Strategies: 2015 Guideline Statement. J Clin Epidemiol. 2016;75:40-6. doi:10.1016/j.jclinepi.2016.01.021.

17. Higgins JPT, Altman DG, Gøtzsche PC, Jüni P, Moher D, Oxman AD, et al. The Cochrane Collaboration's tool for assessing risk of bias in randomised trials. BMJ. 2011;343:d5928. doi:10.1136/bmj.d5928.

18. Kim SY, Park JE, Lee YJ, Seo H-J, Sheen S-S, Hahn S, et al. Testing a tool for assessing the risk of bias for nonrandomized studies showed moderate reliability and promising validity. J Clin Epidemiol. 2013;66:408-14. doi:10.1016/j.jclinepi.2012.09.016.

19. Shea BJ, Reeves BC, Wells G, Thuku M, Hamel C, Moran J, et al. AMSTAR 2: a critical appraisal tool for systematic reviews that include randomised or non-randomised studies of healthcare interventions, or both. BMJ. 2017;358:j4008. doi:10.1136/bmj.j4008.

20. Wierman HR, Wadland WR, Walters M, Kuhn C, Farrington S. Nonpharmacological Management of Agitation in Hospitalized Patients with Late-Stage Dementia A Pilot Study. J Gerontol Nurs. 2011;37:44-8. 
21. Sampson EL, Vickerstaff V, Lietz S, Orrell M. Improving the care of people with dementia in general hospitals: evaluation of a whole-system train-thetrainer model. Int Psychogeriatr. 2017;29:605-14. doi:10.1017/S1041610216002222.

22. Luxford K, Axam A, Hasnip F, Dobrohotoff J, Strudwick M, Reeve R, et al. Improving clinician-carer communication for safer hospital care: A study of the 'TOP 5' strategy in patients with dementia. Int J Qual Health Care. 2015;27:175-82. doi:10.1093/intqhc/mzv026.

23. Isaac LM, Buggy E, Sharma A, Karberis A, Maddock KM, Weston KM. Enhancing hospital care of patients with cognitive impairment. Int J Health Care Qual Assur. 2018;31:173-86. doi:10.1108/IJHCQA-11-2016-0173.

24. Hobday JV, Gaugler JE, Mittelman MS. Feasibility and Utility of Online Dementia Care Training for Hospital Staff The CARES (R) Dementia-Friendly Hospital (TM) Program. Res Gerontol Nurs. 2017;10:58-65. doi:10.3928/19404921-20170131-01.

25. Hasemann W, Tolson D, Godwin J, Spirig R, Frei IA, Kressig RW. A before and after study of a nurse led comprehensive delirium management programme (DemDel) for older acute care inpatients with cognitive impairment. Int J Nurs Stud. 2016;53:27-38. doi:10.1016/j.ijnurstu.2015.08.003.

26. O'Brien R, Goldberg SE, Pilnick A, Beeke S, Schneider J, Sartain K, et al. The VOICE study - A before and after study of a dementia communication skills training course. PLoS One. 2018;13:e0198567. doi:10.1371/journal.pone.0198567.

27. Eggenberger E, Myllymaki J, Kolb C, Martschin R, Bollheimer LC, Sieber C. We cannot care alone. Volunteers in dementia care at Nurnberg General Hospital. [German]. Z Gerontol Geriatr. 2013;46:226-32. doi:10.1007/s00391-013-0480-1.

28. Toye C, Slatyer S, Quested E, Bronson M, Hill A, Fountaine J, et al. Obtaining information from family caregivers to inform hospital care for people with dementia: A pilot study. Int J Older People Nurs. 2019;14:e12219.

29. Naylor MD, Hirschman KB, Hanlon AL, Bowles KH, Bradway C, McCauley KM, Pauly MV. Comparison of evidence-based interventions on outcomes of hospitalized, cognitively impaired older adults. J Comp Eff Res. 2014;3:245-57. doi:10.2217/cer.14.14.

30. Boltz M, Chippendale T, Resnick B, Galvin JE. Testing family-centered, function-focused care in hospitalized persons with dementia. Neurodegenerative disease management. 2015;5:203-15. doi:10.2217/nmt.15.10.

31. Schindel Martin L, Gillies L, Coker E, Pizzacalla A, Montemuro M, Suva G, McLelland V. An Education Intervention to Enhance Staff Self-Efficacy to Provide Dementia Care in an Acute Care Hospital in Canada: A Nonrandomized Controlled Study. Am J Alzheimers Dis Other Demen. 2016;31:664-77. doi:10.1177/1533317516668574.

32. Travers C, Henderson A, Graham F, Beattie E. CogChamps: impact of a project to educate nurses about delirium and improve the quality of care for hospitalized patients with cognitive impairment. BMC Health Serv Res 2018. doi:10.1186/s12913-018-3286-4.

33. Blair A, Anderson K, Bateman C, Haapala I, Biggs S, Kurrle S. The "Golden Angels": effects of trained volunteers on specialling and readmission rates for people with dementia and delirium in rural hospitals. Int Psychogeriatr. 2018;30:1707-16. doi:10.1017/S1041610218000911.

34. Scerri A, Innes A, Scerri C. Dementia training programmes for staff working in general hospital settings - a systematic review of the literature. Aging and mental health. 2017;21:783-96. doi:10.1080/13607863.2016.1231170.

35. Smith TO, Hameed YA, Cross JL, Henderson C, Sahota O, Fox C. Enhanced rehabilitation and care models for adults with dementia following hip fracture surgery. Cochrane Database of Systematic Reviews. 2015.

36. Sherriff C-A, Mathews J, Reynish EL, Shenkin SD. Music therapy for neuropsychiatric symptoms in the general hospital: A systematic literature review. Music and Medicine. 2017;9:217-26.

37. Benner P, Tanner C, Chesla C. Expertise in Nursing Practice: Caring, Clinical Judgement, and Ethcis. New York: Springer Publishing Company; 2009.

38. Surr CA, Gates C. What works in delivering dementia education or training to hospital staff? A critical synthesis of the evidence. Int J Nurs Stud. 2017;75:172-88. doi:10.1016/j.jinurstu.2017.08.002.

39. McCormack B, McCance TV. Development of a framework for person-centred nursing. J Adv Nurs. 2006;56:472-9. doi:10.1111/j.13652648.2006.04042.x.

40. Burgstaller M, Mayer H, Schiess C, Saxer S. Experiences and needs of relatives of people with dementia in acute hospitals-A meta-synthesis of qualitative studies. J Clin Nurs. 2018;27:502-15. doi:10.1111/jocn.13934.

41. Edvardsson D, Fetherstonhaugh D, Nay R. Promoting a continuation of self and normality: person-centred care as described by people with dementia, their family members and aged care staff. J Clin Nurs. 2010;19:2611-8. doi:10.1111/j.1365-2702.2009.03143.x.

42. Mukadam N, Sampson EL. A systematic review of the prevalence, associations and outcomes of dementia in older general hospital inpatients. Int Psychogeriatr. 2011;23:344-55. doi:10.1017/S1041610210001717.

43. Zekry D, Herrmann FR, Grandjean R, Meynet M-P, Michel J-P, Gold G, Krause K-H. Demented versus non-demented very old inpatients: the same comorbidities but poorer functional and nutritional status. Age Ageing. 2008;37:83-9. doi:10.1093/ageing/afm132.

44. Reilly JC, Houghton C. The experiences and perceptions of care in acute settings for patients living with dementia: A qualitative evidence synthesis. Int $\mathrm{J}$ Nurs Stud. 2019;96:82-90. doi:10.1016/j.ijnurstu.2019.04.018.

45. Minary L, Trompette J, Kivits J, Cambon L, Tarquinio C, Alla F. Which design to evaluate complex interventions? Toward a methodological framework through a systematic review. BMC Med Res Methodol. 2019;19:92. doi:10.1186/s12874-019-0736-6.

\section{Supplementary Information}

- Additional file 1: Search strategy for all databases (.docx)

- Additional file 2: Risk of bias of included studies (.docx)

- Additional file 3: Detailed information about the findings of the included studies (.docx)

Page $10 / 20$ 


\section{Tables}

Table 1: Characteristics of included studies 


\begin{tabular}{|c|c|c|c|c|}
\hline $\begin{array}{l}\text { Author (Year), Country, Study } \\
\text { Design } \\
\text { Aim }\end{array}$ & \multicolumn{2}{|l|}{ Participants } & Intervention and Comparison & $\begin{array}{l}\text { Outcomes (Systematic } \\
\text { Reviews) } \\
\text { Outcomes and Measures, } \\
\text { Timepoint (Interventional } \\
\text { studies) }\end{array}$ \\
\hline \multicolumn{5}{|c|}{ Educational programmes } \\
\hline $\begin{array}{l}\text { Abley et al. (2019), UK, } \\
\text { Systematic review } \\
\text { To review the evidence on } \\
\text { educational interventions } \\
\text { about hospital care for older } \\
\text { people with cognitive } \\
\text { impairment }\end{array}$ & \multicolumn{2}{|c|}{$\begin{array}{l}\text { Healthcare professionals at in- } \\
\text { patient and out-patient wards and } \\
\text { departments within general hospitals } \\
\text { Participants were not described in } \\
\text { further detail. }\end{array}$} & $\begin{array}{l}\text { Dementia care training: } \\
\text { 1. classroom teaching ranging from 2-10 hours in length } \\
\text { 2. specially designed educational DVD } \\
\text { 3. dementia training in the ED } \\
\text { Delirium and dementia training: } \\
\text { 1. three online learning modules with access to an educational resource officer, } \\
\text { aimed specifically at nurses } \\
\text { 2. one other module was aimed at all disciplines and involved attending two face-to- } \\
\text { face study days } \\
\text { Comparison: NI }\end{array}$ & $\begin{array}{l}\text { Staff: } \\
\text { 1. Dementia knowledge } \\
\text { 2. Dementia confidence } \\
\text { 3. Self-efficacy } \\
\text { 4. Beliefs and attitudes } \\
\text { 5. Communication } \\
\text { techniques } \\
\text { 6. Palliative care } \\
\text { consultations }\end{array}$ \\
\hline $\begin{array}{l}\text { Scerri et al. (2017), UK, } \\
\text { Systematic review } \\
\text { To collect the current } \\
\text { evidence on dementia training } \\
\text { programmes for staff working } \\
\text { in general hospitals }\end{array}$ & \multicolumn{2}{|c|}{$\begin{array}{l}\text { Healthcare staff (predominately } \\
\text { nurses) and Dementia Champions } \\
\text { working in a general hospital. A few } \\
\text { studies included ancillary staff (such } \\
\text { as porters and security staff). }\end{array}$} & $\begin{array}{l}\text { Dementia training programmes: Most programmes were based on a needs analysis } \\
\text { and aimed not only to provide knowledge and skills but also to empower hospital staff. } \\
\text { The most used theoretical approach was the person-centred care model from Kitwood. } \\
\text { Duration varied between } 2 \text { hours and } 12 \text { days. Most programmes were held in repeated } \\
\text { face-to-face sessions (duration: } 30-45 \text { minutes). } \\
\text { Comparison: NI }\end{array}$ & $\begin{array}{l}\text { Patient: } \\
\text { 1. Reduction in aggressive } \\
\text { behaviour of patients } \\
\text { Staff: } \\
\text { 1. Knowledge } \\
\text { 2. Changes in beliefs about } \\
\text { challenging behaviour } \\
\text { 3. Self-efficacy } \\
\text { 4. Confidence } \\
\text { 5. Burnout } \\
\text { 6. Satisfaction with } \\
\text { working with people with } \\
\text { dementia } \\
\text { 7. Attitudes towards people } \\
\text { with dementia } \\
\text { 8. Change in staff } \\
\text { behaviours and practices }\end{array}$ \\
\hline $\begin{array}{l}\text { Eggenberger et al. (2013), } \\
\text { Germany, Before-after study } \\
\text { To present the preliminary } \\
\text { evaluation results of a } \\
\text { volunteer training programme }\end{array}$ & \multicolumn{2}{|c|}{$\begin{array}{l}\text { Volunteers }(\mathrm{n}=17) \text { : } \\
\begin{array}{l|l}\text { Age: Mean (range) } & \underline{\text { Sex: } \mathrm{n}(\%)} \\
60.5(48-79) & \begin{array}{l}\text { Female: } \\
16(94)\end{array} \\
- & -\end{array}\end{array}$} & $\begin{array}{l}\text { Volunteer training: Two day-long and two half-day education sessions for volunteers } \\
\text { from a multi-professional training team. Contents included dementia, life situations of } \\
\text { older people, gerontology, communication with people with dementia, ethical } \\
\text { decisions, dying in hospital, activities with people with dementia, care of people with } \\
\text { dementia, nutrition, role and identity of volunteers and ward routines }\end{array}$ & $\begin{array}{l}\text { Volunteers: } \\
\begin{array}{l}\text { 1. Skills and attitudes } \\
\text { (self-assessment } \\
\text { questionnaire) }\end{array} \\
\text { 2. Knowledge about } \\
\text { dementia and the } \\
\text { hospital (knowledge } \\
\text { test) }\end{array}$ \\
\hline $\begin{array}{l}\text { To determine whether } \\
\text { dementia care knowledge } \\
\text { significantly increased } \\
\text { following completion of the } \\
\text { CARES Dementia Friendly } \\
\text { Hospital Programme }\end{array}$ & \multicolumn{2}{|c|}{$\begin{array}{l}\text { Nursing assistants and allied } \\
\text { hospital workers }(\mathrm{n}=25) \text { : } \\
\begin{array}{l|l}\text { Age: Mean (range) } & \underline{\text { Sex: }} \mathrm{n}(\%) \\
41.36(13.29) & \begin{array}{l}\text { Female: } \\
24(96)\end{array}\end{array}\end{array}$} & $\begin{array}{l}\text { The CARES }(\mathrm{C}=\text { connect with the person, } \mathrm{A}=\text { assess behaviour, } \mathrm{R}=\text { respond } \\
\text { appropriately, } \mathrm{E}=\text { evaluate what works, } \mathrm{S}=\text { share with others) Dementia Friendly } \\
\text { Hospital Programme. This was an online training programme with four modules: } \\
\text { introduction to dementia-friendly care, communicating with patients, dementia-related } \\
\text { behaviour, wandering and falls. The programme contained audio-narrated texts, video } \\
\text { scenarios and case studies with real case scenarios. }\end{array}$ & $\begin{array}{l}\text { Staff: } \\
\begin{array}{l}\text { 1. Dementia care } \\
\text { knowledge (self- } \\
\text { developed measure) }\end{array} \\
\text { Timepoint: Pre-course and } \\
\text { after course. The average } \\
\text { duration between the two } \\
\text { tests was } 7.96 \text { days. }\end{array}$ \\
\hline $\begin{array}{l}\text { To evaluate the effectiveness } \\
\text { and acceptability of a } \\
\text { communication skills training } \\
\text { intervention }\end{array}$ & \multicolumn{2}{|c|}{$\begin{array}{l}\begin{array}{l}\text { Nurses, doctors and allied health } \\
\text { professionals }(\mathrm{n}=43) \text { : }\end{array} \\
\qquad \begin{array}{c|l}\text { Agge: } & \begin{array}{l}\text { Sex: } \mathrm{n}(\%) \\
\text { NI }\end{array} \\
\begin{array}{l}\text { Female: } \\
40(89)\end{array}\end{array}\end{array}$} & $\begin{array}{l}\text { VOICE for Dementia training: This was a systematically developed dementia training } \\
\text { programme based on actual evidence and expert views. It was a two-day course (with a } \\
\text { one-month interval between the sessions) containing communication skills training } \\
\text { with simulations, real video data, small group discussions, e-learning and reflective } \\
\text { practice }\end{array}$ & $\begin{array}{l}\text { Staff: } \\
\begin{array}{l}\text { 1. Confidence in caring for } \\
\text { a person with dementia } \\
\text { (The Confidence in } \\
\text { Dementia Scale and } \\
\text { three additional } \\
\text { questions) } \\
\text { 2. Knowledge of } \\
\text { communication in } \\
\text { dementia (Dementia }\end{array}\end{array}$ \\
\hline
\end{tabular}

Page $12 / 20$ 


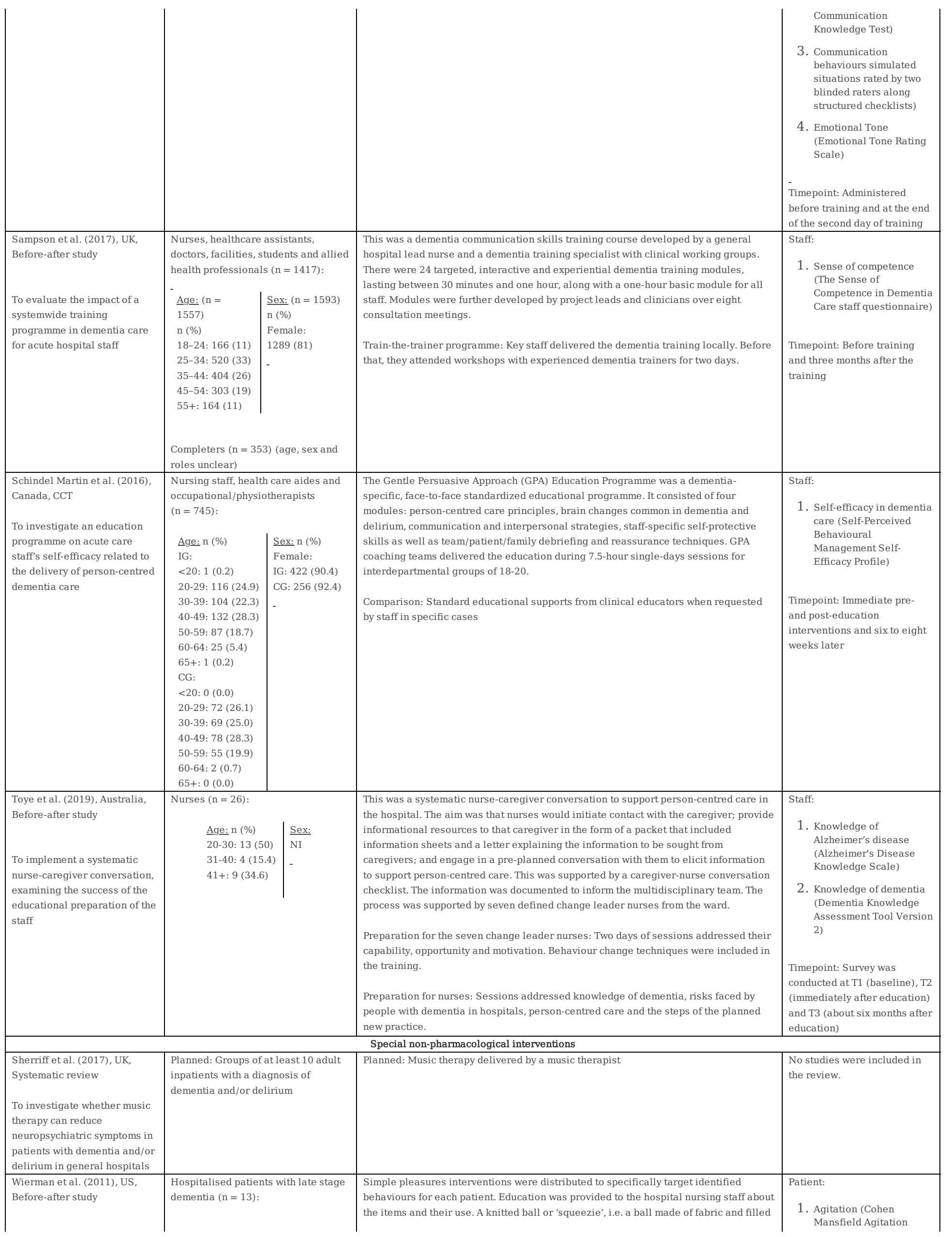

Page 13/20 
with rice, seeds or beads, was given to all patients to target generalized anxiety and

To assess the feasibility of simple pleasures interventions in the hospital setting and their impact on agitation in patients with latestage dementia

\begin{tabular}{|l|l|} 
Age: Mean & $\underline{\text { Sex: \% }}$ \\
Group A: 84 & Female: \\
Group B: 86 & Group A: \\
& 64 \\
& Group B: \\
& 33 \\
\hline Average length of & \\
stay: & \\
Group A: 3 days & \\
Group B: 4.5 days &
\end{tabular}
restlessness.

One additional item from the list below was distributed by the evaluating geriatric team member based on the patient's behaviours:

-Wave machines to target repetitive hand movements

-A stuffed butterfly, fish or animal to target verbal repetitiveness

-Activity aprons and sensory vests to target repetitive motor patterns or pulling at

medical devices

-Fleece-covered warm water bottles or warmed fabric bags filled with rice to target screaming

-A fleece muff to target general agitation and anxiety

-Look-inside tackle boxes and/or purses in which treasures were safely contained to target hand restlessness or wandering

The patient was seen by a geriatric team member every 48 hours to ensure the items were still present and to re-educate the nursing staff on their use.

Group A received the intervention at the initial evaluation, group B received it 24 hours after the initial evaluation.

\section{Delirium management programme}

\section{Hasemann et al. (2016),}

Switzerland, Before-after study

To investigate the influence of a screening and action algorithm on the development of delirium severity and duration in patients with cognitive impairment and on the use of prescribed benzodiazepines

\begin{tabular}{|c|c|}
\hline Patients with de & entia $(n=268)$ : \\
\hline $\begin{array}{l}\text { Age: } \quad \text { Mean } \\
\text { (SD) } \\
\text { IG: } 81.8(6.3) \\
\text { CG: } 81.6(6.3)\end{array}$ & $\begin{array}{l}\text { Sex: } n(\%) \\
\text { IG: Female: } 76 \\
(55.1) \\
\text { CG: Female: } 71 \\
(54.6)\end{array}$ \\
\hline $\begin{array}{l}\underline{\text { Initial Swiss }} \\
\underline{\text { mini-mental }} \\
\text { status: Median } \\
\text { (Min;Max) } \\
\text { IG: } 22(0 ; 29) \\
\text { CG: } 24(8 ; 29)\end{array}$ & $\begin{array}{l}\text { Clock drawing } \\
\text { test: Median } \\
\text { (Min;Max) } \\
\text { IG: } 4(0 ; 7) \\
\text { CG: } 5(0 ; 6)\end{array}$ \\
\hline $\begin{array}{l}\text { Delirium risk: } \\
\text { Median } \\
\text { (Min;Max) } \\
\text { IG: medium } \\
\text { risk } \\
\text { CG: medium } \\
\text { risk }\end{array}$ & $\begin{array}{l}\text { Hospitalisation } \\
\text { duration: Median } \\
\text { (Min;Max) } \\
\text { IG: } 10.3 \\
(1.3 ; 48.9) \\
\text { CG: } 9.7 \\
(3.2 ; 36.7)\end{array}$ \\
\hline
\end{tabular}

The "Dem Del" was a nurse-led intervention with six components:

(1) An educational package for nurses and physicians regarding cognitive impairment and delirium (professions separated from each other). Support was provided by specially trained ward nurses and case conferences by the study team.

(2) On admission, nurses screened all patients aged 70 and over for cognitive impairment. Signs of cognitive impairment were discussed with the physicians within a short period of time.

(3) Based on the nurses' screening results, the physicians prescribed or revised PRN medication for delirium according to the prepared recommendation of the hospital.

(4) A priority list of evidence-based interdisciplinary measures to prevent and treat delirium in patients at risk was provided to the staff.

(5) Nurses screened for symptoms of delirium on every shift using the Delirium Observation Screening Scale for five days after admission. If there was a suspicion of delirium, the nurse conducted an in-depth assessment.

(6) If delirium was identified, prescribed medication was administered, and the interdisciplinary intervention was implemented.

Comparison: Care as usual
Inventory)

Timepoint: Conducted within 24 hours of initial assessment and then every 48 to 72 hours Patient:

1. Delirium severity (Delirium Rating Scale, Revised-98)

2. Delirium duration (daily chart review)

3. Prescribed and administered medications (daily chart review)

Timepoint: Daily assessment Inpatient rehabilitation intervention

\begin{tabular}{l|l|}
$\begin{array}{l}\text { Smith etal. (2015), UK, } \\
\text { Systematic review }\end{array}$ & $\begin{array}{l}\text { Persons 65 years and older with any } \\
\text { form of dementia who underwent hip } \\
\text { fracture surgery for a proximal } \\
\text { femoral fracture } \\
\text { effectiveness of models of } \\
\text { care, including enhanced } \\
\text { rehabilitation strategies for } \\
\text { people with dementia } \\
\text { following hip fracture surgery }\end{array}$ \\
\end{tabular}

1. Enhanced interdisciplinary inpatient rehabilitation and care models

2. Enhanced interdisciplinary inpatient and home-based rehabilitation and care models

3. Geriatrician-led inpatient management (compared to orthopaedic-led management)

Comparison: Usual care (including conventional rehabilitation)

3. Complications

\section{Boltz et al. (2015), US,}

Comparative repeated

measures design

To te st the impact of Fam-FFC among hospitalised persons with dementia and their family caregivers regarding ADLperformance after discharge, as well as other patient and caregiver outcomes
Patients with dementia and family caregivers $(\mathrm{n}=84$ dyads):
Family-/person-centred programmes

Combined FFC with a family-centred approach (Fam-FFC) in an educationalempowerment intervention for family caregivers

Component 1: Environmental and policy assessments and adaptions (such as bedside whiteboards, access to inexpensive hearing amplifiers, activity cart/supplies and mobility devices)

Component 2: Staff education and training regarding cognitive impairment, FFC and family involvement

Component 3: Ongoing training and motivation of nursing staff

Component 4: FamPath care pathway with family/patient education, joint family caregiver/nurse assessment and jointly developed individualised goals and treatment plans, delivered to post-acute care providers.

Comparison: FFC education using a modified version of the staff education component
Patient:

1. Functional performance

2. Mortality

4. Length of hospital stay

5. Number of prescribed drugs on discharge

6. Discharge destination

7. Frequency of hospital admissions

8. Attendance in the emergency room

9. Incidence of falls

10. Incidence of delirium

Patient:

1. ADL performance (Barthel Index)

2. Walking performance (Single item from the Barthel Index that measures the ability to walk 50 feet)

3. Gait and balance (Tinetti Scale)

4. Severity of delirium (Delirium Severity Scale) 


\begin{tabular}{|c|c|c|c|c|}
\hline & $\begin{array}{l}\text { Age: } \\
\text { Patients: Mean } \\
\text { (SD) } \\
\text { IG: } 81.0(8.5) \\
\text { CG: } 83.8(6.5) \\
\text { Family } \\
\text { caregivers: } \\
\text { years: n (\%) } \\
\text { IG: } \\
\text { 31-45: } 2 \text { (5) } \\
\text { 46-65: } 25(57) \\
\text { 66-80: } 9(20) \\
\text { Over 80: } 8(18) \\
\text { CG: } \\
\text { 31-45: } 3(7 \%) \\
\text { 46-65: } 20(48 \%) \\
\text { 66-80: } 10(24 \%) \\
\text { Over 80: } 9(21 \%) \\
\text { AD8-Score: } \\
\text { Mean (SD) } \\
\text { IG: } 4.0(2.1) \\
\text { CG: } 4.4(2.0)\end{array}$ & $\begin{array}{l}\text { Sex: } \\
\text { Patients: n (\%) } \\
\text { IG: Female 23 } \\
\text { (52) } \\
\text { CG: Female 28 } \\
\text { (67) } \\
\\
\text { Family } \\
\text { caregivers: } \\
\text { NI }\end{array}$ & 5 & $\begin{array}{l}\text { Relatives: } \\
\text { Preparedness for caregiving } \\
\text { (Preparedness for Caregiving } \\
\text { Scale) } \\
\text { Caregiver anxiety and } \\
\text { depression (two subscales } \\
\text { within the Hospital Anxiety } \\
\text { and Depression Scale } \\
\text { (HADS): HADS-A and HADS- } \\
\text { D) } \\
\text { Mutuality (Mutuality Scale) } \\
\text { Caregiver strain (Modified } \\
\text { Caregiver Strain Index) } \\
\text { FCG involvement in care } \\
\text { (bedside log completed by the } \\
\text { caregivers) } \\
\\
\text { Timepoint: Data assessment } \\
\text { within } 48 \text { hours of admission, } \\
\text { at discharge and at } 14 \text { days } \\
\text { and } 60 \text { days post discharge }\end{array}$ \\
\hline $\begin{array}{l}\text { Isaac et al. (2018), Australia, } \\
\text { Before-after study } \\
\text { To investigate whether the } \\
\text { TOP } 5 \text { strategy could improve } \\
\text { patients' hospital experience } \\
\text { and positively impact health } \\
\text { service provision and } \\
\text { outcomes. The impact of the } \\
\text { TOP } 5 \text { intervention on carer } \\
\text { and staff experiences was also } \\
\text { investigated. }\end{array}$ & $\begin{array}{l}\text { Patients with demen } \\
\text { staff }(\mathrm{n}=43) \text { : } \\
\qquad \begin{array}{l}\text { Age: } \\
\text { NI }\end{array}\end{array}$ & $\begin{array}{l}\text { tia }(\mathrm{n}=\mathrm{NI}) \text { and } \\
\frac{\text { Sex: }}{\mathrm{NI}}\end{array}$ & $\begin{array}{l}\text { The TOP } 5 \text { initiative comprised the ward nursing staff talking to the carer and } \\
\text { obtaining non-clinical information from the carer to help personalise the care of the } \\
\text { patient. The carer was encouraged to identify up to five personalised care strategies } \\
\text { that could be utilised by staff. The information was documented on the TOP5 strategy } \\
\text { form, which was in a prominent position in the patient's bedside notes. } \\
\text { This was accompanied by education sessions for staff regarding the TOP } 5 \text { intervention } \\
\text { and related topics (a total of } 44 \text { education sessions in an eight-month period during } \\
\text { baseline data collection, with } 30 \text { education sessions during the pilot phase) }\end{array}$ & $\begin{array}{l}\text { Patient: } \\
\text { 1. Total number of falls } \\
\text { 2. Average length of stay } \\
\text { 3. Use of 'specials' (one-to- } \\
\text { one nursing care) } \\
\text { 4. Complaints made to the } \\
\text { hospital spe cifically } \\
\text { related to } \\
\text { communication issues } \\
\text { Staff: } \\
\text { 1. Perceptions of } \\
\text { confidence (questions on } \\
\text { a 4-point Likert scale) } \\
\text { 2. Comfort engaging with } \\
\text { family carers (questions } \\
\text { on a 4-point Likert scale) } \\
\text { Timepoint: Data collection at } \\
\text { baseline (for } 12 \text { months pre- } \\
\text { intervention), in the pilot } \\
\text { phase (14 months) and in the } \\
\text { establishment phase (12 } \\
\text { months) }\end{array}$ \\
\hline $\begin{array}{l}\text { Luxford et al. (2015), Australia } \\
\text { Uncontrolled before-after } \\
\text { study } \\
\text { To investigate the impact of } \\
\text { the TOP } 5 \text { clinician-carer } \\
\text { communication tool on patient } \\
\text { safety indicators and on } \\
\text { staffing for one-to-one nursing }\end{array}$ & $\begin{array}{l}\text { Patients with demen } \\
\text { staff }(\mathrm{n}=798) \text { : } \\
\text { - } \\
\text { Nge: } \\
\text { - } \\
\text { Staff surveys were } \mathrm{r} \\
\text { time points. }\end{array}$ & $\begin{array}{l}\text { Sex: } \\
\frac{\mathrm{NI}}{\mathrm{NI}} \\
\text { eturned relatives and } \\
\end{array}$ & $\begin{array}{l}\text { TOP } 5 \text { engaged clinical staff in a structured process with carers to elicit and record up } \\
\text { to five important non-clinical tips and management strategies to aid communication } \\
\text { and support personalized care. The five tips were recorded on a one-page form, which } \\
\text { was then attached to the patient's charts at the bedside. } \\
\text { Each hospital identified a local implementation team to champion TOP } 5 \text { use. Staff } \\
\text { education was provided in the use of TOP } 5 \text { at each hospital. }\end{array}$ & 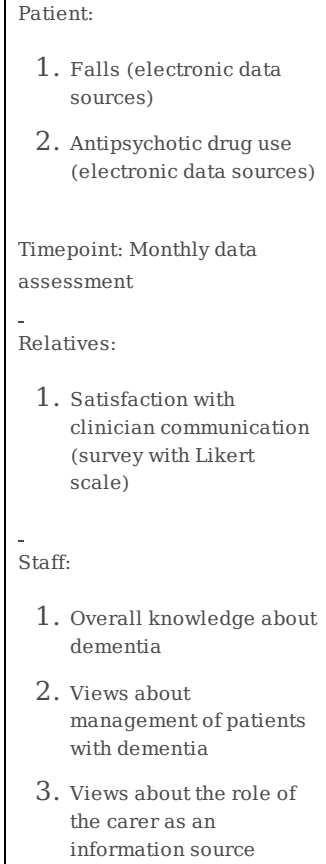 \\
\hline
\end{tabular}




\begin{tabular}{|c|c|c|c|c|}
\hline & & & & $\begin{array}{l}\text { 4. Value placed on carer } \\
\text { input for patients with } \\
\text { dementia } \\
\text { 5. Views about obtaining } \\
\text { key strategies from } \\
\text { carers to help manage } \\
\text { care } \\
\text { 6. Level of confidence in } \\
\text { caring for patients with } \\
\text { dementia } \\
\text { 7. Level of comfort in } \\
\text { engaging with carers (all } \\
\text { staff outcomes were } \\
\text { assessed with a survey } \\
\text { with Likert scale) } \\
\text { Timepoint: Survey data were } \\
\text { collected pre-intervention at } 6 \\
\text { and } 12 \text { months } \\
\text { Organisation: } \\
\text { 1. One-to-one nursing } \\
\text { (monthly data from } \\
\text { hospitals) }\end{array}$ \\
\hline \multicolumn{5}{|c|}{ Specially trained nurses } \\
\hline $\begin{array}{l}\text { Naylor et al. (2014), US, } \\
\text { Cluster RCT } \\
\text { To compare the effectiveness } \\
\text { of three evidence-based } \\
\text { interventions of varying } \\
\text { intensity designed to improve } \\
\text { outcomes of hospitalized } \\
\text { cognitively impaired older } \\
\text { adults }\end{array}$ & 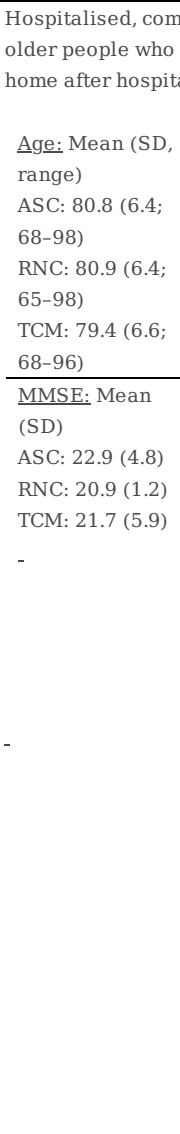 & $\begin{array}{l}\text { anity-dwelling } \\
\text { anned to return } \\
\text { stay }(\mathrm{n}=202) \text { : } \\
\text { Sex: } \mathrm{n}(\%) \\
\text { Female: } \\
\text { ASC: } 39 \text { (60) } \\
\text { RNC: } 47 \\
(66.2) \\
\text { TCM: } 40 \\
(60.6) \\
\text { Delirium } \\
\text { present: } \\
\text { ASC: } \mathrm{n}=12 \\
(18.5) \\
\text { RNC: } \mathrm{n}=21 \\
(29.6) \\
\text { TCM: } \mathrm{n}=12 \\
(18.2)\end{array}$ & $\begin{array}{l}\text { Augmented Standard Care (ASC): Within } 24 \text { hours of hospitalisation, cognitive } \\
\text { screening was completed by research assistants; delirium assessment continued } \\
\text { throughout hospitalization. Within two hours of assessments, research assistants } \\
\text { communicated cognitive findings to nurses, physicians and social workers and } \\
\text { documented findings in patients' medical records. } \\
\text { Resource Nurse Care (RNC): After a web-based training and a test, } 59 \text { hospital } \\
\text { employed RNs were considered as resource nurses. These resource nurses provided } \\
\text { direct care and/or coached other nurses involved in the care of enrolled patients } \\
\text { during the hospital stay. Throughout the study, resource nurses participated in } \\
\text { seminars provided by the study team. } \\
\text { Transitional Care Model (TCM): Master's prepared APNs implemented the } \\
\text { intervention. In addition to the orientation designed for resource nurses, APNs } \\
\text { completed TCM-specific web-based modules and individualized clinical experiences. } \\
\text { The TCM protocol consisted of hospital and home visits, at least one physician follow- } \\
\text { up visit, telephone outreach and availability seven days a week. Two full-time and one } \\
\text { part-time APN implemented the TCM protocol. }\end{array}$ & $\begin{array}{l}\text { Patient: } \\
\text { 1. Time to first } \\
\text { rehospitalisation or } \\
\text { death (from date of } \\
\text { hospital discharge to } \\
\text { date of event) } \\
\text { 2. Total number and days of } \\
\text { all-cause } \\
\text { rehospitalisation } \\
\text { (reported to research } \\
\text { assistants during in- } \\
\text { person interviews with } \\
\text { caregivers and validated } \\
\text { using medical records) } \\
\\
\text { Timepoint: 30-day increments } \\
\text { through six months post-index } \\
\text { hospital discharge }\end{array}$ \\
\hline $\begin{array}{l}\text { Travers et al. (2018), } \\
\text { Australia, CCT } \\
\text { To investigate patient } \\
\text { outcomes of the Cognition } \\
\text { Champions programme }\end{array}$ & $\begin{array}{l}\text { Patients with dem } \\
\text { - }\end{array}$ & tia $(\mathrm{n}=181)$ : & $\begin{array}{l}\text { The CogChamps Programme aimed to upskill RNs to improve the capacity of an acute- } \\
\text { care nursing workforce to recognize patients with cognitive impairment and provide } \\
\text { high quality care. The CogChamps were provided in-depth education on caring for } \\
\text { cognitively impaired patients in hospital and were encouraged to develop 'Action } \\
\text { Plans for Practice Change'. } \\
\text { Comparison: Standard care in a comparable hospital }\end{array}$ & $\begin{array}{l}\text { Patient: } \\
\text { 1. Prescribed medication } \\
\text { 2. Activity } \\
\text { 3. Signs of agitation/pain } \\
\text { 4. Confusion/disorientation } \\
\text { 5. Mealtime difficulty } \\
\text { 6. Adverse outcomes for } \\
\text { patients } \\
\text { Staff: } \\
\text { 1. Number of patients } \\
\text { assessed for cognitive }\end{array}$ \\
\hline
\end{tabular}

Page 16/20 
2. Number of occasions patients who showed confusion were reoriented by nurse

3. Number of occasions patients who experienced meal-time difficulty received appropriate assistance

4. How often the nurses introduced

himself/herself when approaching the patient

5. How often the nurse addressed the patient by his/her name when approaching the patient

6. Nurse explained the action/procedure in easy to understand terms (all outcomes were assessed by a chart

audit/observations by trained research nurses)

Timepoint: Baseline (pre-

intervention), Time 2

(immediately

following the CogChamps'

education), Time 3 (post

action plan implementation),

and at Follow-Up (three

months following the

withdrawal of the research

team)

Volunteer programme

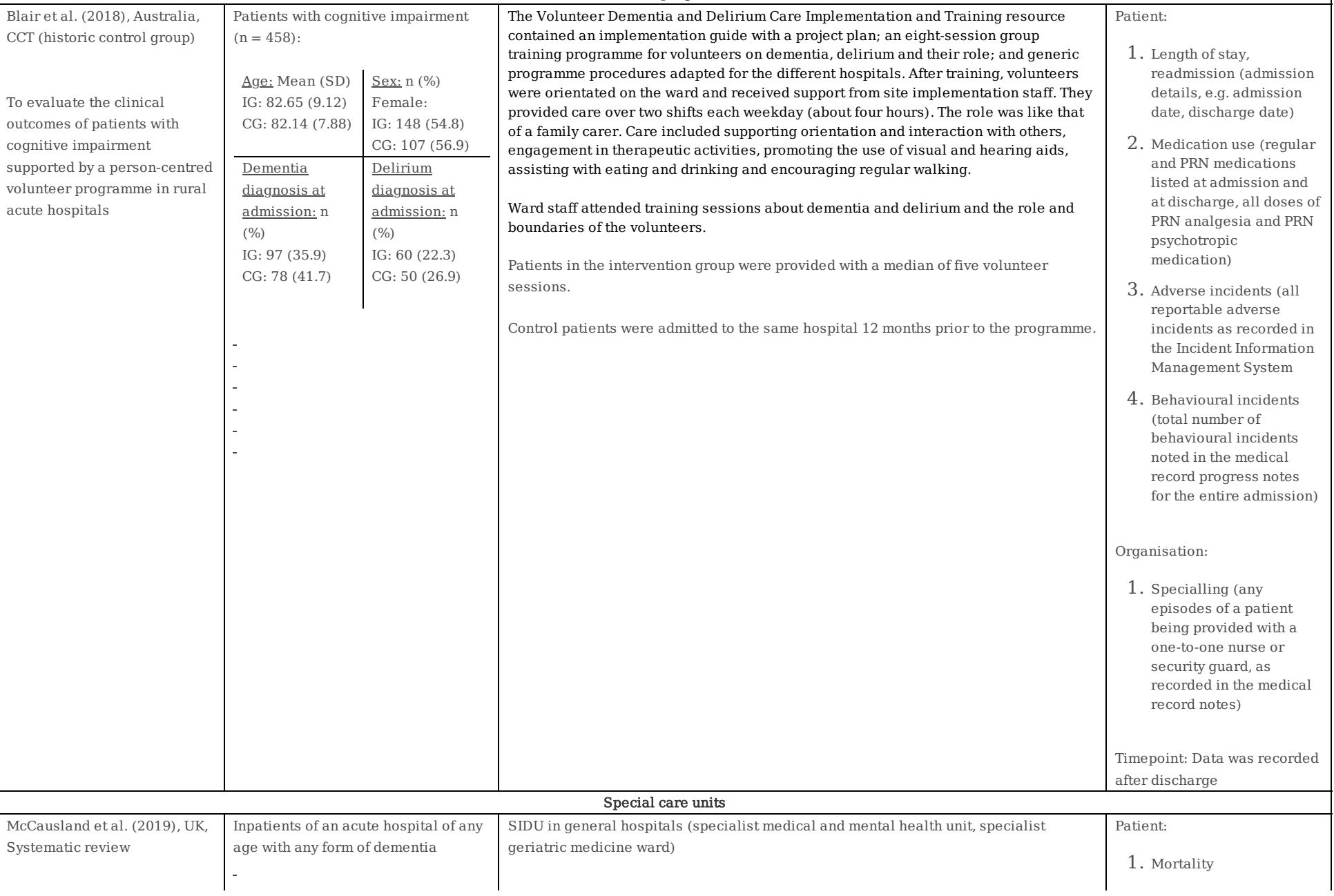

Page 17/20 


\begin{tabular}{|c|c|c|}
\hline $\begin{array}{l}\text { To determine } \\
\text { whether acute hospital SIDUs } \\
\text { are effective in improving } \\
\text { outcomes for patients living } \\
\text { with dementia compared to } \\
\text { SWCs }\end{array}$ & Comparison: Standard care ward & $\begin{array}{l}\text { 2. Length of stay } \\
\text { 3. Readmission rate } \\
\text { 4. Rates of BPSD } \\
\text { 5. Incidence of delirium } \\
\text { 6. New antipsychotic } \\
\text { medications } \\
\text { 7. Overall antipsychotic } \\
\text { prescription rate } \\
\text { 8. Days spent at home } \\
\text { 9. Discharged to home } \\
\text { 10. Barthel Index score } \\
\text { 11. Cognitive impairment } \\
\text { 12. Quality of life } \\
\text { 13. Positive mood/engaged } \\
\text { 14. Patient active and } \\
\text { interacting with others } \\
\text { Relatives: } \\
\text { 1. Carer strain } \\
\text { 2. Carer psychological } \\
\text { well-being } \\
\text { Staff: } \\
\text { 1. Documentation of } \\
\text { treatment decisions } \\
\text { 2. Accurate drug history } \\
\text { 3. Accurate co-morbidities } \\
\text { documented } \\
\text { r. Collateral history taken } \\
\text { regarding cognition } \\
\text { documented }\end{array}$ \\
\hline
\end{tabular}

Abbreviations: ADL $=$ activities of daily living, APN $=$ advanced practice nurse, ASC $=$ Augmented Standard Care, BPSD $=$ behavioural and psychological symptoms of dementia, $\mathrm{CCT}=$ controlled clinical trial, $\mathrm{CG}=$ comparison group, $\mathrm{CI}=$ cognitive impairment, $\mathrm{ED}=$ emergency department, Fam-FFC $=$ family-centred function focused care, FCG $=$ family caregivers, FFC $=$ function focused care, GPA = Gentle Persuasive Approach, IG = intervention group, MD = mean difference, MMSE $=$ mini mental state examination, $\mathrm{NI}=$ no information available, $\mathrm{PRN}=$ pro re nata, $\mathrm{RN}=$ registered nurse, $\mathrm{RNC}=$ Resource Nurse Care, $\mathrm{RCT}=$ randomised controlled trial, $\mathrm{SD}=$ standard deviation, SIDU $=$ special inpatient dementia unit, SWC $=$ standard inpatient ward care, TCM = Transitional Care Model, UK = United Kingdom, US $=$ United States

We have only reported on quantitative findings. Data were only extracted for dementia-specific issues, e.g. if a systematic review included studies about delirium interventions, we have not reported these results.

Table 2: Reported outcomes and effects I 


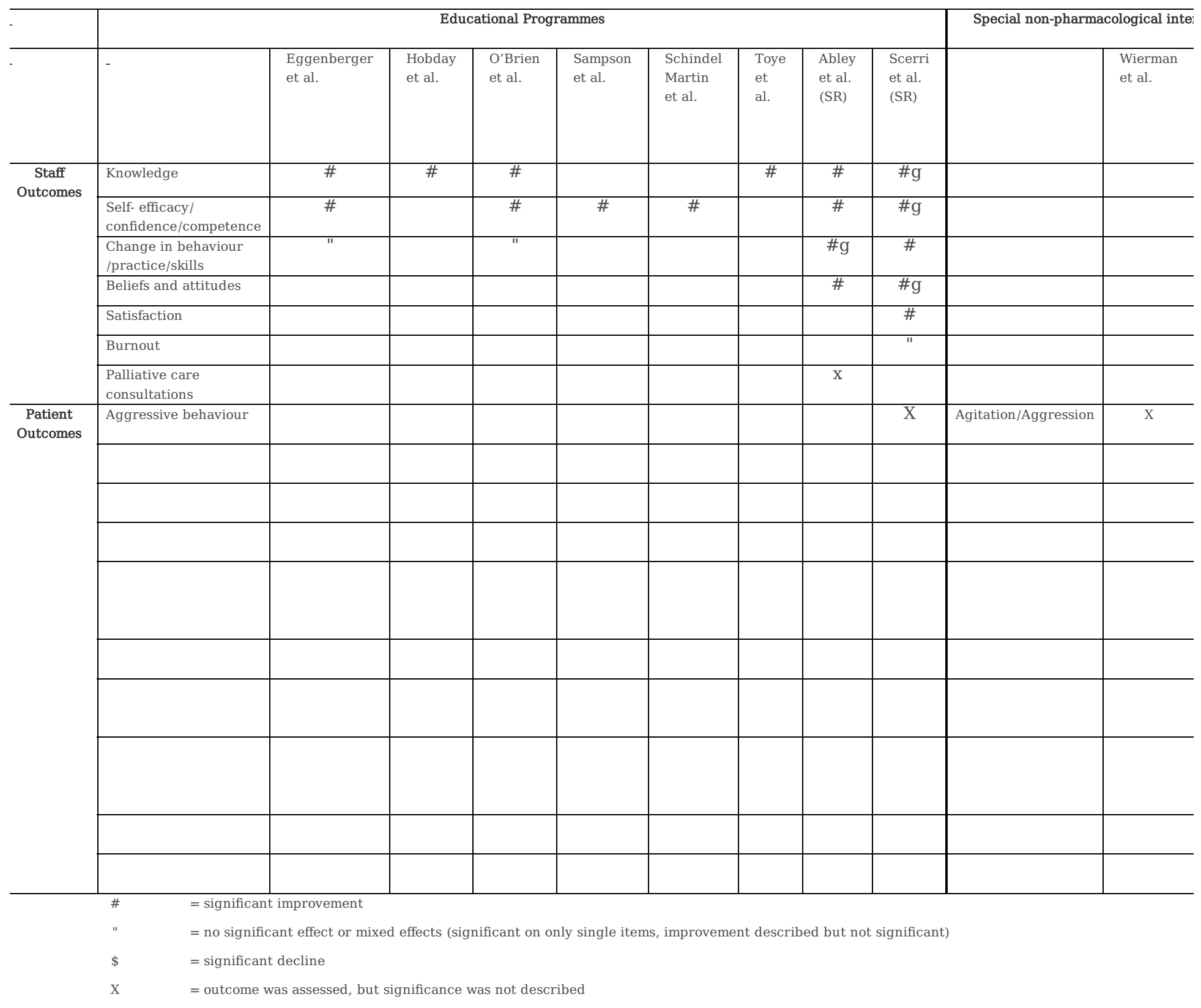

White = interventional studies; grey = systematic reviews

Figures 


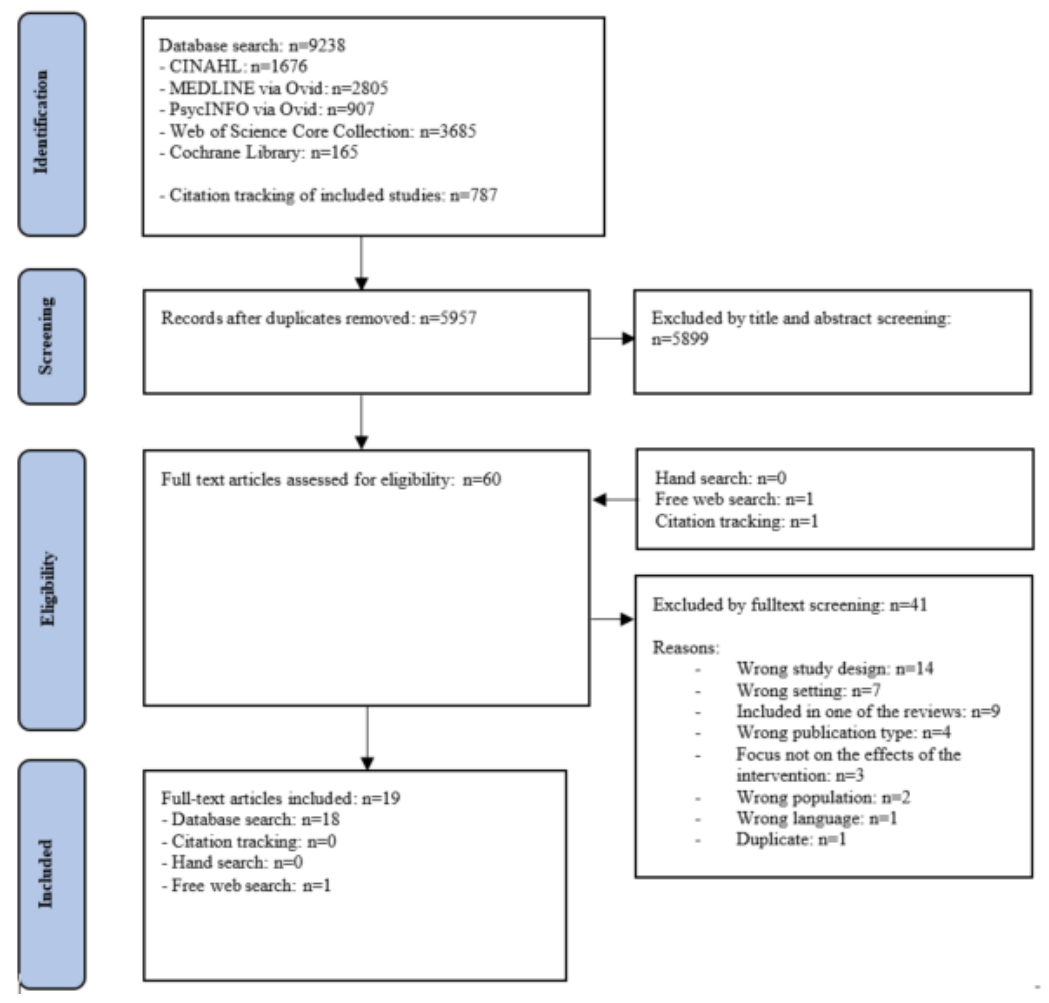

Figure 1

Flow chart of the search and selection process

\section{Supplementary Files}

This is a list of supplementary files associated with this preprint. Click to download.

- Additionalfile2.docx

- PRISMAchecklist.doc

- Additionalfile1.docx

- Additionalfile3.docx 